\title{
Numerical Prediction of Differences in Micromechanical Fracture Sequence in Notched and Un-Notched Wires for Civil Engineering Applications
}

\author{
Adewole, K.K. ${ }^{* *}$ and Bull, S.J. ${ }^{1}$
}

\begin{abstract}
The need to employ simulation-based investigations of fracture of civil engineering structures has been emphasised recently in literature. In this paper, three dimensional finite element simulations revealed that the cup and cone fracture process in channel-shaped notched wire for civil engineering applications begins with a slant fracture at the root of the outer edge of the channel-shaped notch and follows a slant to flat fracture sequence. These results demonstrate that the fracture origin in cup and cone fracture in notched wires for civil engineering applications does not necessarily begin with a flat fracture at the center of the wire and does not necessarily follows the flat to slant fracture sequence or propagation generally reported in literature. These results further demonstrate the need to employ simulation-based methodologies in conjunction with or as an alternative to purely experimental fractographic analysis for an accurate failure analysis of wires used for civil engineering applications.
\end{abstract}

Keywords: Cup and cone fracture; failure analysis; finite element; fractography; wire.

\section{Introduction}

Failure analyses of civil engineering structures and structural components, such as the failure analysis of the broken wires of suspension bridge conducted by Mahmoud [1] and the failure analysis of ruptured prestressed concrete pipe conducted by the United States Bureau of Reclamation [2] are conducted to identify the cause(s) of failure to prevent future failure recurrence and/or for quality control of civil engineering materials. The fracture performance of steel wires used for prestressing steel and concrete structures, and for the construction of suspended bridges among other applications in civil engineering is a major concern in civil engineering construction and maintenance of these wire-reinforced structures [3]. Fractography (the visual examination of fracture surfaces) is fundamental to failure analysis and is an important tool for quality control [4]. For failure analysis, fractography is conducted to gain an overall understanding of the fracture, locate the fracture origin(s), determine the fracture sequence, and identify any macroscopic features or microstructural abnormalities that caused or contributed to fracture initiation or propagation [4].

1 School of Chemical Engineering and Advanced Materials, Newcastle University, Newcastle upon Tyne, United Kingdom, NE1 7RU.

* Correspponding author, e-mail: kkadewole@yahoo.com; Tel: +2348092540024

Note: Discussion is expected before November, $1^{\text {st }} 2014$, and will be published in the "Civil Engineering Dimension" volume 17, number 1, March 2015.

Received 21 January 2014; revised 23 June 2014; accepted 08 July 2014.
In particular, locating the fracture origin and understanding the sequence of fracture propagation are fundamental to successful failure analyses [4]. However, in practice, obtaining the characteristic marks produced by fracture initiation and propagation that are required for successful failure analyses might be impossible because these fracture features might be destroyed by the failure incident or drastically altered by post-fracture events, thereby making a conclusive fracture interpretation and failure analysis difficult, if not impossible [4].

The published works on failure analysis and fracture performance of steel wires used in civil engineering applications are the works of Toribio and Ayaso [3, 5] and Toribio and Valiente [6] on concrete prestressing wires, and that of Mahmoud [1] on bridge cable wires. Other published works on failure analysis and fracture performance of steel wires includes the work of Mapelli and Barella [7] on cable-way rope made up of many wires and the work of Smith and Easterling [8] on high tensile strength carbon steel wires used as cables for towing target behind aircraft.

All these published works were based on purely experimental classical fracture mechanics approach and fractographic analysis of failed wires. The experimental classical fracture mechanics works were based on non-standardised fracture mechanics specimens as standard fracture mechanics test specimens could not be manufactured from the wires owing to their size. The fractographic analysis conducted by these authors to understand the micromechanism of failure, microscopic topography and 
the micro-fracture maps of wires were based on the scanning electron microscope (SEM) image of the fractured wire surfaces. The applicability of traditional classical fracture mechanics in predicting fracture of civil engineering steel structural materials and members remains a concern, which has necessitated the need to employ micromechanical fracture mechanics for the prediction of fracture and fracture performance of civil engineering steel structural materials and components [9]. Micromechanical-based fracture mechanics serves as an alternative to classical fracture mechanics when standard classical fracture mechanics specimens cannot be obtained and when a safe use of the classical fracture mechanics concepts cannot be insured [10]. The need to employ simulation-based investigation of fracture of civil engineering structures has been emphasised recently by Fell and Kanvinde [9]. Simulation-based investigation reduces the need for costly large-scale testing, allows for parametric studies which can examine situations which may not be feasible to test and provides researchers with a tool to develop insights into localized effects that trigger fracture [9].

The cup and cone fracture exhibited by many ductile structural alloys subjected to tensile loading is generally characterized by a flat fracture (attributed to tensile fracture) in the center of the specimen and a slant fracture ("shear lips" attributed to shear fracture) at the outer regions of the specimen [11-15]. In the published experimental and finite element simulation works on the cup and cone fracture in unnotched tensile specimen [11-15], the cup and cone fracture in un-notched tensile specimen was reported to start with a flat fracture at the center of the specimen followed by a transition to slant fracture at the outer regions of the specimen. Similarly, Panontin and Sheppard [16] in their experimental and finite element simulation works reported that the cup and cone fracture in notched tensile specimen started at the center of the specimen. Panontin and Sheppard [16], based their conclusion on the fractographic analysis of sections of the tensile specimens obtained from tensile tests that were interrupted before the specimens were loaded to their fracture initiation loads and not on the actual fractographic analysis of the fractured notched tensile specimens. They further corroborated their conclusion that the cup and cone fracture in the notched tensile specimen started at the center of the specimen based on their observation that at the load corresponding to the fracture initiation load, the maximum/critical void ratio for fracture initiation occurs at the center of the specimen. Their conclusion was not based on the FE prediction of the actual fracture initiation location and the actual fracture propagation sequence.
The fracture initiation at the center of tensile specimen which exhibit a cup and cone fracture is generally attributed to micro-void nucleation at the center of the specimen due to tensile overload of the specimen [13, 17]. The fracture initiation at the center of the specimen in a cup and cone fracture has been attributed to the rapid void growth at the center which leads to fracturing of the centre of the specimen long before the critical strain for shear band formation is reached [17]. The cup and cone failure has also been reported to begin with the flat fracture at the center of the specimen due to the preferential and faster crack growth at the centre of the specimen with high stress triaxiality when compared with a slower crack growth on the outer regions of the specimen with low triaxiality [13]. The transition from flat fracture at the center of the specimen to slant fracture at the outer regions of the specimen has also been attributed to the weak geometrical constraints on shearing at the lateral surface (outer region) of the specimen [13]. In all published works, the successful simulation of the cup and cone failure was based on the ability of the simulations to predict flat fracture initiation in the centre of the specimen, flat fracture extension perpendicular to the loading direction and a final deviation from the original flat crack propagation direction to slant crack propagation. The capturing of these phenomena and the flat to slant fracture sequence are described by Scheider and Brocks [12] as the benchmark for a successful cup and cone prediction.

In this paper, three dimensional finite element (FE) simulations of the cup and cone fracture in unnotched and channel-shaped notched wire test specimens conducted with the elastic-plastic and micro-mechanism based phenomenological shear failure models inbuilt in Abaqus 6.9-1 FE code [18] is presented. The material considered in this study is a typical high strength carbon steel wire used for prestressing and reinforcing civil engineering structures. The channel-shaped notch considered represents one of the geometries of the scratches that are typically found on the surface of the wires as shown in the secondary electron scanning electron micrographs (SEM) in Figure 1, which typically arise from handling damage. Details of the isotropic elasticplastic model and the shear failure criterion employed in the FE simulation can be found in the work of Adewole [18].

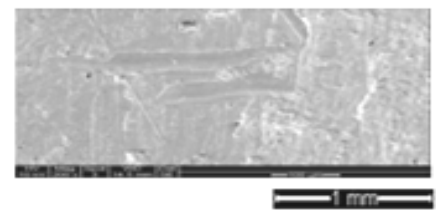

SEM image

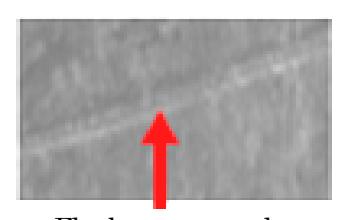

Flat bottom scratch
Figure 1. SEM Images of Wire Surface with Scratches 


\section{Experimental}

The details of the experimental measurements and FE simulations are presented in this section.

\section{Laboratory Tensile Testing}

Un-machined full cross section specimens prepared to the specifications of the ASTM E8M:2009 [19] and BS EN 10002-1:2001[20] standards were tested. The tensile tests were conducted with an Instron universal testing machine (IX 4505) fitted with an Instron 2518 series load cell with a maximum static capacity of $\pm 100 \mathrm{kN}$. The displacement was measured using an Instron 2630-112 clip-on strain gauge extensometer with a $50 \mathrm{~mm}$ gauge length. Ten specimens each of two wire sizes with $12 \mathrm{~mm}$ x $5 \mathrm{~mm}$ and 12 $\mathrm{mm} \times 7 \mathrm{~mm}$ cross-sectional dimensions were tested. Tensile tests were conducted on un-notched specimens and specimens with channel-shaped notch/cut shown in Figures 2(a) and 2(c) respectively for both wire sizes.

\section{Finite Element Tensile Testing Simulation}

Three dimensional FE simulations of the tensile testing of the wire specimens with and without a 2 $\mathrm{mm} \times 2 \mathrm{~mm}$ channel-shaped cut were conducted. The simulation of the tensile testing of the model with the channel-shaped cut was conducted with the same material input used for the simulation of the tensile testing of the wire without the channelshaped cut, which was obtained from the laboratory tensile testing of the wire specimens without the channel-shaped cut. The calibrated shear damage and fracture modelling parameters used for the FE simulations are fracture strain of 0.3451 , shear stress ratio of 12.5 , strain rate of $0.000125 \mathrm{~s}^{-1}$ and a material parameter $K_{\mathrm{s}}$ of 0.3 . Details of the phenomenological curve fitting process employed to obtain these calibrated values have been published by Adewole [18]. The outer regions of the models of the wire specimens with and without the channelshaped cut were meshed with $1 \mathrm{~mm} \times 1 \mathrm{~mm}$ x $1 \mathrm{~mm}$ C3D8R elements (8-node hexahedral linear brick reduced integration elements with hourglass control). The centre of the un-notched specimens and the regions around the channel-shaped cut were meshed with a refined mesh with $0.1 \mathrm{~mm} \times 0.1 \mathrm{~mm} \times 1 \mathrm{~mm}$ elements as shown in Figures 2(b) and (d) respectively. The $0.1 \mathrm{~mm}$ x $0.1 \mathrm{~mm}$ x $1 \mathrm{~mm}$ elements size was established through a mesh convergence study as the optimum mesh size for the accurate prediction of the cup and cone fracture prediction/simulation.

The FE simulations were conducted by fixing the left hand ends of the models and subjecting the right hand ends, which are free to move only in the direction of the tensile load to a longitudinal displacement as shown in Figures 2(b) and (d). The maximum material stiffness degradation, $D_{\max }$,

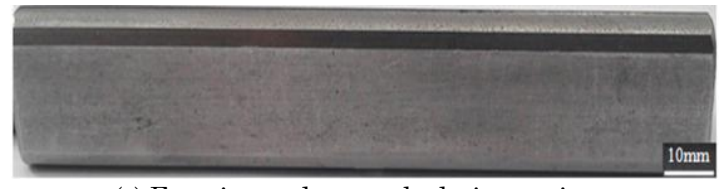

(a) Experimental un-notched wire specimen

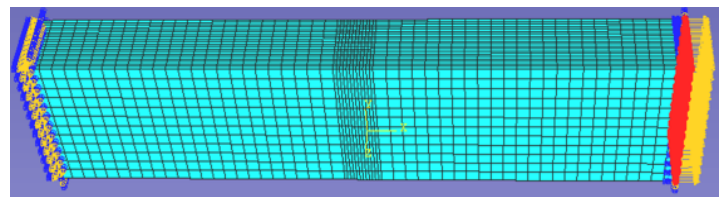

(b) FE model of un-notched wire specimen

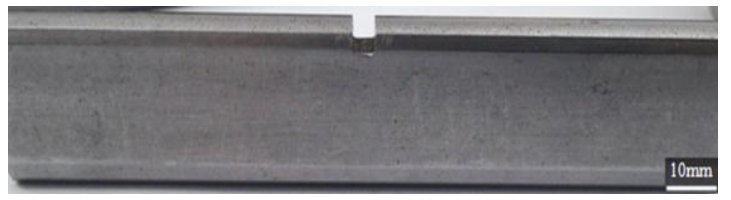

(c) Experimental notched wire specimen

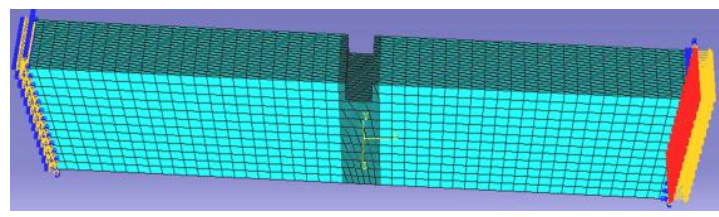

(d) FE notched wire specimen

Figure 2. Laboratory and FE Models of Notched and Unnotched Wire Specimens

value of 1.0 and the elements removal option were employed for the shear damage evolution and failure. This implies that failure, typified by element removal occurred at any part of the model where the shear damage initiation criteria value is equal to the specified maximum material stiffness degradation, $D_{\max }$, value of 1.0 .

\section{Results}

The experimental and FE predicted results for unnotched and channel-shaped notched wire specimens are presented as follows:

\section{Experimental and FE Results for Un-notched Wire Specimens}

The experimental and FE predicted force-displacement curves for the specimens of the two wire sizes without the channel cut normalised with the experimental ultimate load and displacement at fracture are shown in Figure 3. The deformed shapes of the un-notched wire models at the various stages of the cup and cone fracture formation showing the equivalent plastic strain and the shear damage initition criteria during the flat fracture initiation, flat fracture propagation, transition from flat fracture to slant fracture, slant fracture propagation and the completely fractured wire models are shown in Figures 4 to 8. In Figures 4 to 8, where the initiated voids/cracks and the crack propagation within the wire models are not visible in the deformed meshed images, the deformed shapes in wireframes are presented. The maximum and 
minimum values of both the equivalent plastic strain and the shear damage initiation criteria are indicated in red and blue respectively in the contour plots. The fractured un-notched wire specimen obtained from the laboratory tensile test is shown in Figure 8(c).

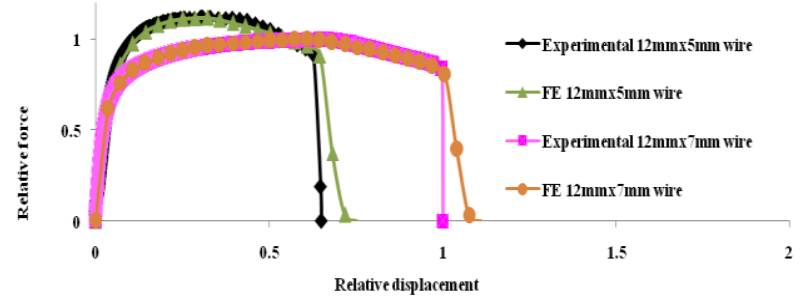

Figure 3. Experimental and FE Force-displacement Curves for Un-notched Wire Specimens

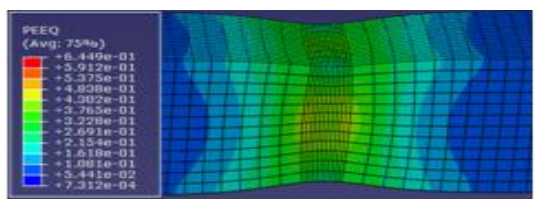

(a) Equivalent plastic strain distribution

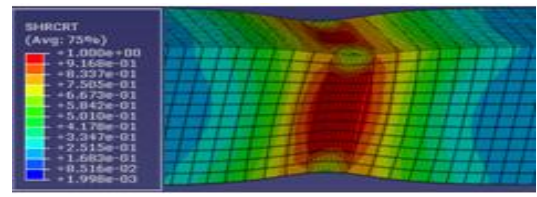

(b) Shear damage initiation criteria distribution

Initiated flat fracture

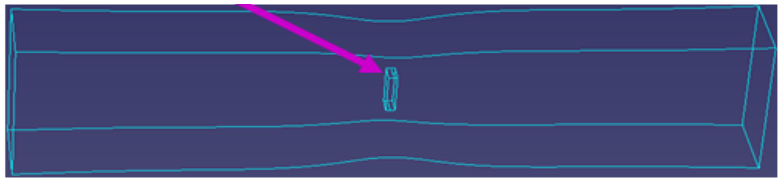

(c) Deformed shape of specimen in wireframe showing initiated flat crack

Figure 4. Deformed Shapes of Un-notched Wire Specimen during Fracture Initiation

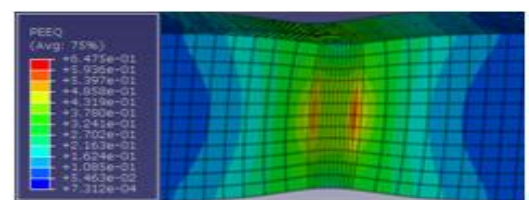

(a) Equivalent plastic strain distribution

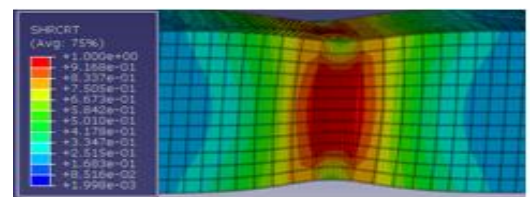

(b) Shear damage initiation criteria distribution

Propagated flat fracture

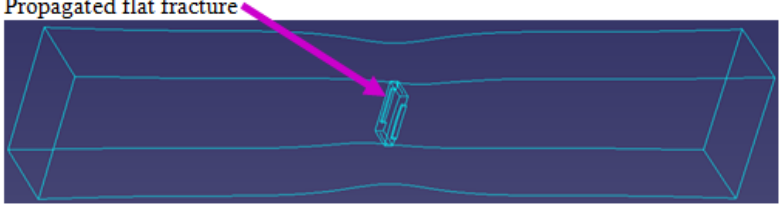

(c) Deformed shape of specimen in wireframe showing the propagated flat crack

Figure 5. Deformed Shapes of Un-notched Wire Specimen at the End of Flat Fracture Propagation

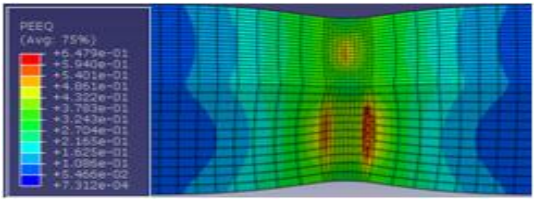

(a) Equivalent plastic strain distribution

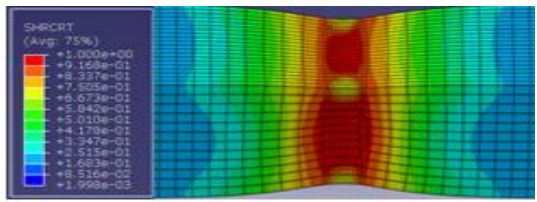

(b) Shear damage initiation criteria distribution

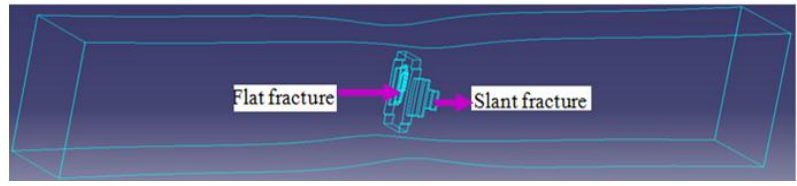

(c) Deformed shape of specimen in wireframe

Figure 6. Deformed Shapes of Un-notched Wire Specimen during Transition from Flat to Slant Fracture

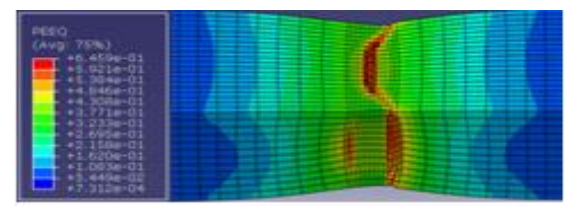

(a) Equivalent plastic strain distribution

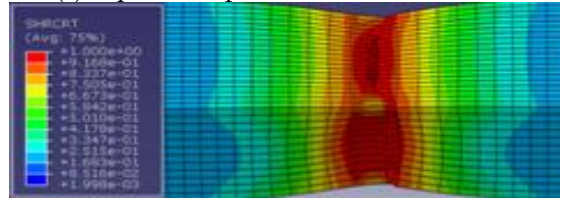

(b) Shear damage initiation criteria distribution Flat fracture Propagated slant fracture

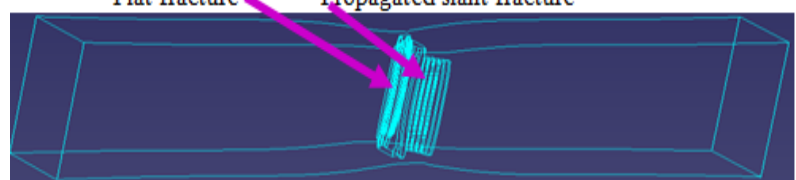

(c) Deformed shape of specimen in wireframe showing propagated slant fracture

Figure 7. Deformed Shapes of Un-notched Wire Specimen Showing Slant Fracture Propagation

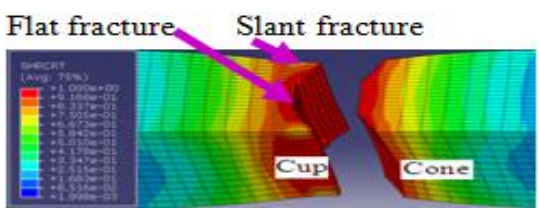

(a) Equivalent plastic strain distribution

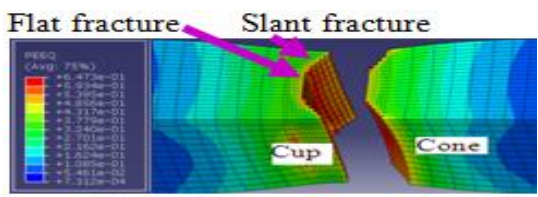

(b) Shear damage initiation criteria distribution

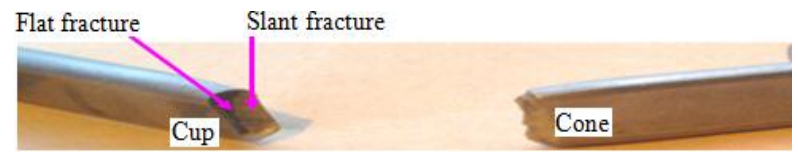

(c) Fractured wire specimen from laboratory tensile test

Figure 8. Experimental and FE Predicted Fractured Unnotched Wire Specimens with a Cup and Cone Fracture 


\section{Experimental and FE Predicted Results for Channel-shaped Notched Wire Specimens}

The experimental and FE predicted force-displacement curves for the specimens of the two wire sizes with the channel cut normalised with the experimental ultimate load and displacement at fracture are shown in Figure 9. The deformed shapes of the model of the wire specimen with the channel-shaped cut at the various stages of the cup and cone formation showing the slant fracture initiation, slant fracture propagation, propagated slant fracture, transition from slant to flat fracture (i.e. flat fracture initiation) and the propagated flat fracture at the region around the root of the channel-shaped notch are shown in Figures 10 to 14. The deformed shapes of the model of wire specimen with the channelshaped cut during the simultaneous propagation of the flat and slant fracture along/across the width of the specimen and the completely fractured wire model are shown in Figures 15 and 16 respectively. The fractured channel-shaped notched wire specimen obtained from the laboratory tensile test is shown in Figure 16(e).

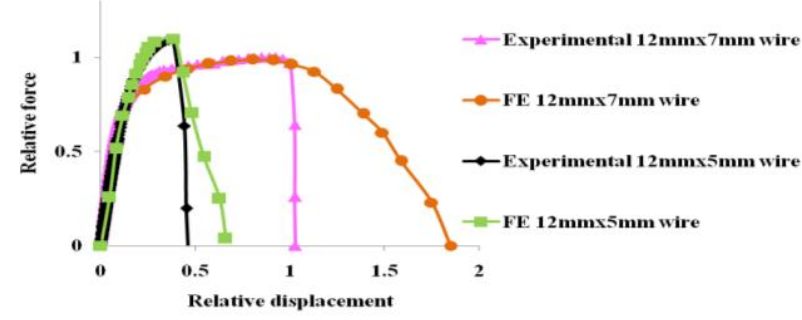

Figure 9. Experimental and FE Force-displacement Curves for Channel-shaped Notched Wire Specimens

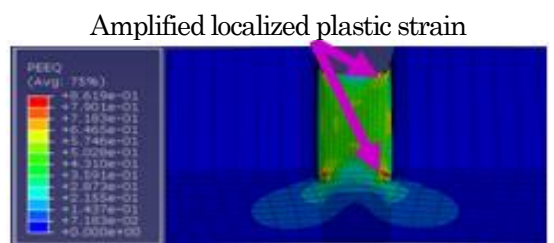

(a) Equivalent plastic strain distribution

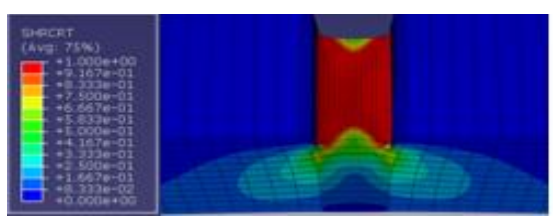

(b) Shear damage initiation criteria distribution

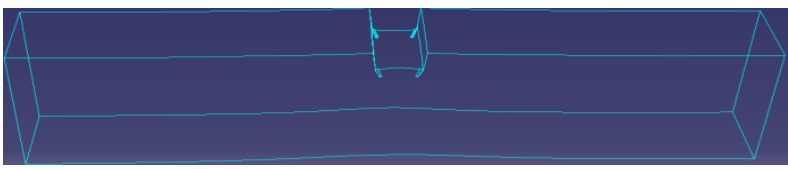

(c) Deformed shape of specimen in wireframe

Figure 10. Deformed Shapes of Channel-shaped Notched Wire Specimen during Slant Fracture Initiation

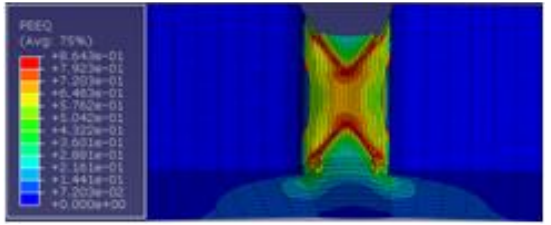

(a) Equivalent plastic strain distribution

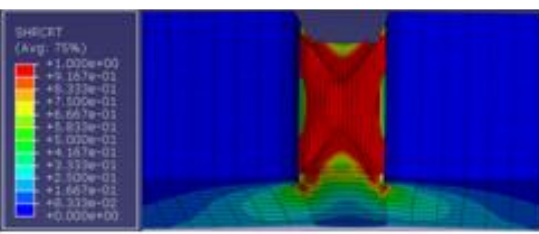

(b) Shear damage initiation criteria distribution

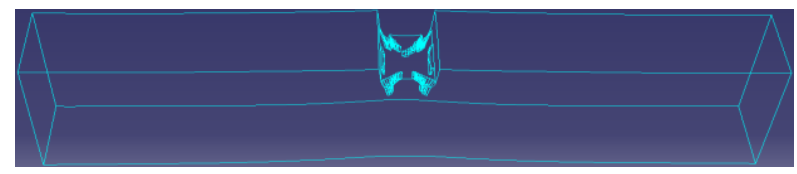

(c) Deformed shape of specimen in wireframe

Figure 11. Deformed Shapes of Channel-shaped Notched Wire Specimen during Slant Fracture Propagation

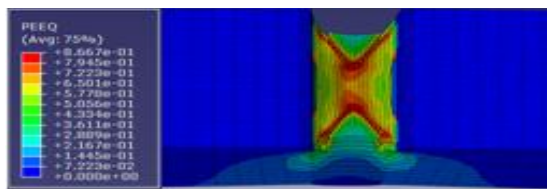

(a) Equivalent plastic strain distribution

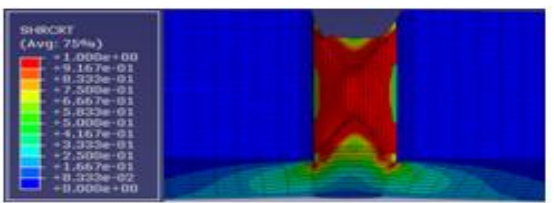

(b) Shear damage initiation criteria distribution

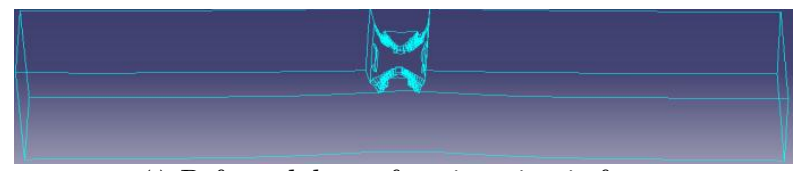

(c) Deformed shape of specimen in wireframe

Figure 12. Deformed Shapes of Channel-shaped Notched Wire Specimen at the End of Slant Fracture Propagation

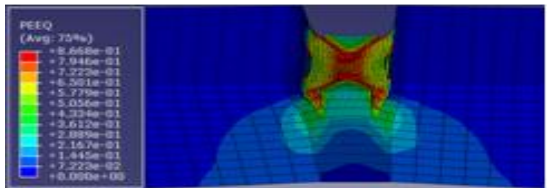

(a) Equivalent plastic strain distribution

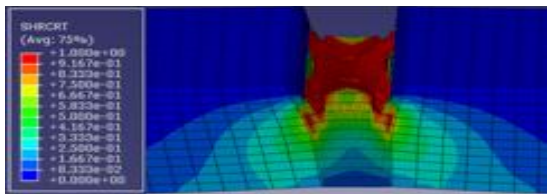

(b) Shear damage initiation criteria distribution

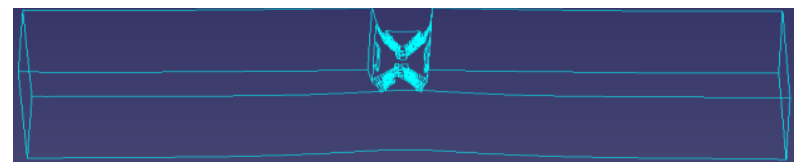

(c) Deformed shape of specimen in wireframe

Figure 13. Deformed Shapes of Channel-shaped Notched Wire Specimen during Transition from Slant to Flat Fracture 


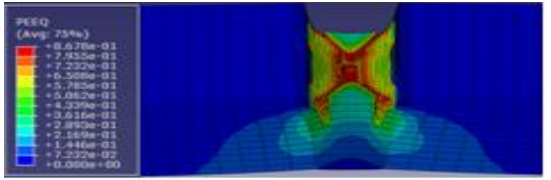

(a) Equivalent plastic strain distribution

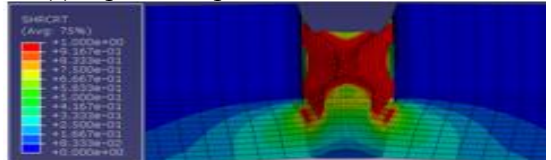

(b) Shear damage initiation criteria distribution

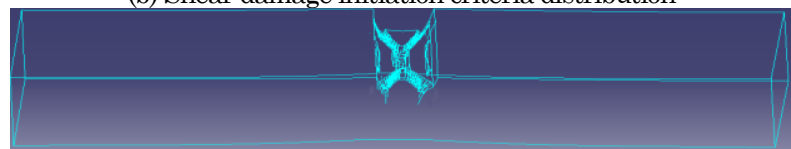

(c) Deformed shape of specimen in wireframe at the end of flat fracture propagation.

Figure 14: Deformed Shapes of Channel-shaped Notched Wire Specimen at the End of Flat Fracture Propagation

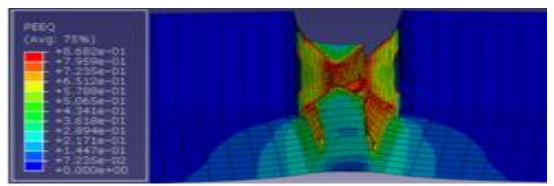

(a) Equivalent plastic strain distribution

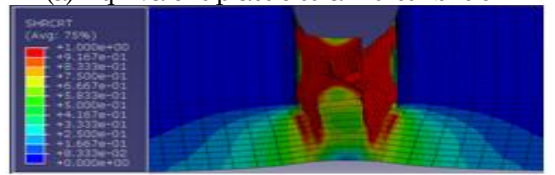

(b) Shear damage initiation criteria distribution

Figure 15. Deformed Shapes of Channel-shaped Notched Wire Specimen during Simultaneous Slant and Flat Fractures Propagation

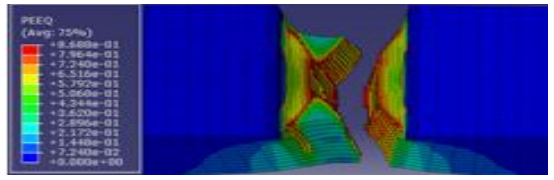

(a) Equivalent plastic strain distribution

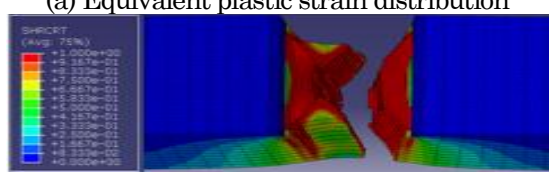

(b) Shear damage initiation criteria distribution

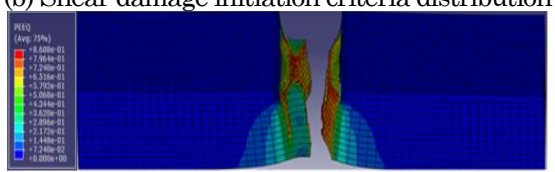

(c) Equivalent plastic strain distribution

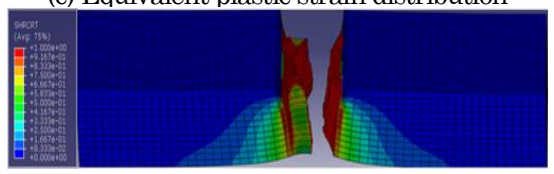

(d) Shear damage initiation criteria distribution

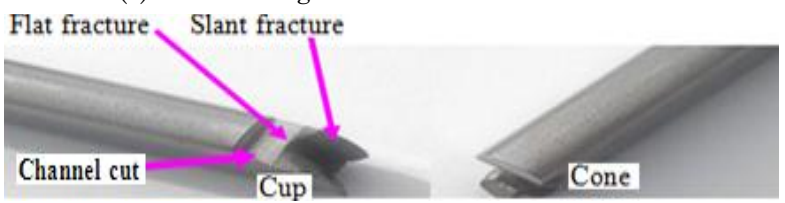

(e) Fractured wire specimen from laboratory tensile test

Figure 16. Completely Fractured Channel-shaped Notched Wire Specimen

\section{Discussion}

The good agreement between the experimental and FE predicted force-displacement curves for the unnotched and channel shaped notched wire specimens shown in Figures 3 and 9 respectively demonstrates the accuracy of the tensile testing simulations. The good agreement between the cup and cone fracture shape exhibited by the experimental and FE modelled un-notched and channel-shaped notched wire specimens shown in Figures 8 and 16 further demonstrates the accuracy of the tensile testing simulations. In Figure 3, the yield and the ultimate loads of the $12 \mathrm{~mm} \times 5 \mathrm{~mm}$ wire are higher than the yield and the ultimate loads of the $12 \mathrm{~mm} \times 7 \mathrm{~mm}$ wires, while the displacement at fracture of the of the $12 \mathrm{~mm} \times 5 \mathrm{~mm}$ wire is lower than that of the 12 $\mathrm{mm} \times 7 \mathrm{~mm}$. This is due to the fact that the $12 \mathrm{~mm} \times$ $5 \mathrm{~mm}$ wire underwent more drawing passes/ processes which reduced the size of the wire and workhardened it. The higher level of workhardening experienced by the $12 \mathrm{~mm}$ x $5 \mathrm{~mm}$ wire explains why the wire has a higher yield and ultimate loads than those of the $12 \mathrm{~mm} \times 7 \mathrm{~mm}$ wire and a lower displacement at fracture than that of the $12 \mathrm{~mm} \times 5$ $\mathrm{mm}$ wire.

In Figures 3 and 9, the load carrying ability of the experimental curves rapidly dropped to zero immediately after fracture initiation at the displacement at fracture of the wire (which coincides with the ultimate load of the notched wire in Figure 9). This demonstrates that the crack initiated at the displacement at fracture of the wire propagated rapidly leading to the rapid fracture of the wire leaving the wire without any load carrying ability. Conversely, the load carrying ability of the FE predicted curves did not rapidly drop to zero as the FE predicted a progressive failure of the wire. The inability of the FE to predict a rapid drop in load as exhibited by the experimental curve is due to the general limitations of the existing/available ductile damage and fracture models (including the phenomenological shear fracture model used in this work) which are only able to predict accurately the elastic and plastic responses of materials up to the beginning of fracture phase which involves micro-crack nucleation and growth [21]. The existing/available ductile damage and fracture models (including the phenomenological shear fracture model used in this work) models the actual material fracture phase which involves macro-crack initiation (occurring by microvoids coalesce) and the fracture development (ductile tearing/ductile crack growth) by element deletion or node separation. Hence these damage and fracture models cannot describe in an adequate form the macrocrack formation that takes place at the last instants of the fracture process [22] and are also yet 
to be able to exactly predict materials fracture trajectory [21]. Consequently, the FE predicted curve did not show a rapid drop to zero of the load carrying ability of the wire because the FE modeled the actual wire fracture phase which involves macro-crack initiation (due to microvoids coalesce) and the fracture development (due to ductile tearing/ductile crack growth) by progressive element deletion and not by the rapid fracture propagation exhibited by the experimental wires.

As shown in Figure 4, fracture initiation started at the the center of the un-notched wire specimen because the equivalent plastic strain and the shear damage initiation criteria are maximum at the center of the un-notched wire specimen. Conversely, fracture initiation started at the root of the outer edge of the channel-shaped notch where the equivalent plastic strain and the shear damage initiation criteria are maximum as shown in Figure 10. The maximum equivalent plastic strain occurs at the root of the notch due to the plastic strain concentration effect of the notch, which results in a high local plastic strain concentration around the notch root symbolised by the red strain contour colour at the four corners of the channel as shown in Figure 10(a). The high local plastic strain concentration at the four corners of the channel is accompanied by a high local strain hardening and a local strain rate which is much higher than the average strain rate, both of which led to the ductile void formation/crack initiation at the four corners of the channel cut.

As shown in Figures 5 to 8, the cup and cone fracture in the un-notched wire specimen proceeded with the flat fracture propagating perpendicularly to the loading direction, transiting to slant fracture and ending with slant fracture propagation, which agrees with the sequence generally reported in the literature. Conversely, the initiated fracture at the four corners of the channel propagated at an approximately 45 degree to the loading direction, thereby forming slant fractures along the shear band formed where the equivalent plastic strain and the shear damage initiation criteria are maximum as shown in Figure 11. The slant fracture ended at about a third of the thickness of the wire as shown in Figure 12 and transited to a flat fracture at the centre of the wire thickness as shown in Figure 13, The initiated flat fracture propagated along the middle of the specimen where the equivalent plastic strain and the shear damage initiation criteria are now maximum as shown in Figure 14. At this stage of the fracture of the channel-shaped notched specimen, the cup and cone fracture (flat fracture at center and slant fractures at both outer regions) is fully formed at the regions of the specimen around the notch as shown in Figure 14. Further straining of the specimen resulted in the simultaneous propagation of both the flat fracture at the center and the slant fractures at the outer regions as shown in Figure 15, leading to the complete separation of the wire specimen with the cup and cone fracture shown in Figure 16.

The predicted cup and cone fracture sequence starting with a slant fracture instead of a flat fracture at the root of the outer edge of the channelshaped notch instead of at the center of the notched specimen presents a different fracture initiation type and a different fracture initiation location compared with the fracture initiation type and the fracture initiation location in notched tensile specimen reported by Panontin and Sheppard [16]. Similarly, the predicted slant to flat fracture propagation sequence in the notched wire specimen presents a different cup and cone fracture propagation sequence compared with the cup and cone fracture propagation sequence in notched specimen reported by Panontin and Sheppard [16]. The fracture initiation type, fracture initiation location and fracture propagation sequence in the cup and cone fracture in the notched wire specimen predicted by the FE simulations presented in this paper which are based on the actual/visible fracture of the wire specimen presents an actual and more verifiable/accurate cup and cone fracture sequence compared with the FE predicted cup and cone fracture sequence in notched tensile specimen presented by Panontin and Sheppard [16]. The cup and cone fracture process (fracture initiation type, fracture initiation location and fracture propagation sequence) presented by Panontin and Sheppard [16] were based on the fractographic analysis of sections of the tensile specimens obtained from tensile tests that were interrupted before the specimens were loaded to their fracture initiation loads and not on the actual fractographic analysis of the fractured notched tensile specimens. The FE predicted cup and cone fracture process presented by Panontin and Sheppard [16] were also based on their observation that at the load corresponding to the fracture initiation load, the maximum/critical void ratio for fracture initiation occurs at the center of the specimen and not the actual/visible FE predicted cup and cone fracture process. Furthermore, the predicted fracture initiation type, fracture initiation location and fracture propagation sequence in the channel-shaped notched wire specimen presented in this paper presents a different fracture initiation type, fracture initiation location and fracture propagation sequence to that reported by the published literature on cup and cone fracture in un-notched tensile specimens.

\section{Conclusions}

The FE simulations revealed that fracture initiation starts with a flat fracture at the center of the unnotched wire specimen while fracture initiation 
starts with a slant fracture at the four outermost corners of the channel-shaped notch in the notched wire specimen. The FE simulations also revealed that the cup and cone fracture process in the unnotched wire specimen follows the flat to slant fracture sequence generally reported in the literature while the cup and cone fracture processes in the channel-shaped wire specimen follows a slant to flat fracture sequence. Thus, through finite element simulation, the differences in fracture origin and in the sequence of the cup and cone fracture in unnotched and channel-shaped notched wire specimens, which show that the cup and cone fracture does not always start with a flat fracture at the center of the wire specimen as is generally reported in published literature, have been established. Consequently, the origin of crack and the direction of crack growth in the cup and cone fracture mode of the channel-shaped notched wire specimen which serves as the road map required by failure analyst to evaluate the fracture of wire have been established. Thus, the origin of crack and the direction of crack growth in the cup and cone fracture mode exhibited by the wire for civil engineering application, particularly where defects might be present in the wire should always be carefully determined as concluding that the failure starts with a flat fracture at the center of the specimen and follows a flat to slant fracture propagation could be misleading. This is due to the fact that concluding that fracture initiation in the cup and cone fracture in wires starts at the center of the wire due micro-void nucleation resulting from a tensile overload instead of microcracking at the tip of defects or notches could lead to a wrong conclusion on the macroscopic features, microstructural abnormalities or defects that caused or contributed to fracture initiation in wires for civil engineering applications.

Furthermore, the fracture origin and fracture sequence or profile in notched wire specimens established by the FE simulation presented in this paper provide useful information that may not be easily obtained from wires that fracture in service as the fracture face of the wires might be unavoidably destroyed in the failure incident or drastically altered by post-fracture events which could lead to a wrong conclusion during failure analysis. Thus in this paper, the need to employ simulation-based methodologies in conjunction with or as an alternative to purely experimental fractographic work for the prediction of the fracture performance, identification of the cause of failure (microstructural abnormalities or defects), the prediction of the micromechanism of failure, microscopic topography and the micro-fracture maps of wires required for fractographic and accurate failure analyses of failed wires for civil engineering applications and other engineering components that fail in tension is demonstrated.

\section{References}

1. Mahmoud, K.M., Fracture Strength for a High Strength Steel Bridge Cable Wire with a Surface Crack. Theoretical and Applied Fracture Mechanics, 48(2), 2007, pp.152-160.

2. United States Bureau of Reclamation, Prestressed Concrete Pipe Failure Jordan Aqueduct, Reach 3. All U.S. Government Documents (Utah Regional Depository), 1994 Paper 284. http:// digitalcommons.usu.edu/govdocs/284. Accessed 20/03/2012.

3. Toribio, J. and Ayaso, F.J., Anisotropic Fracture Behaviour of Cold Drawn Steel: A Materials Science Approach. Materials Science and Engineering A343, 2003, pp. 265-272

4. Vander Voort, G. F., Visual Examination and Light Microscopy, ASM Handbook, Volume 12: Fractography, 1987, pp, 91-165, ASM web. www. asminternational.org. Accessed 25/03/2012.

5. Toribio J. and Ayaso, F. J., Fracture Performance of Progressively Drawn Pearlitic Steel under Triaxial Stress States. Materials Science, 37(5), 2001. pp. 707-717.

6. Toribio, J. and Valiente A., Failure Analysis of Cold Drawn Eutectoid Steel Wires for Prestressed Concrete, Engineering Failure Analysis, 13(3), 2006, pp. 301-311.

7. Mapelli, C. and Barella, S., Failure Analysis of a Cableway Rope, Engineering Failure Analysis, 16(5), July 2009, pp. 1734-1739.

8. Smith, G.D.W., and Easterling, K.E., Handbook of Cases of Histories in Failure Analysis, Vol 2, ASM International, 1993, ISBN: 0-87170-495-1.

9. Fell, B.V. and Kanvinde, A.M., Recent Fracture and Fatigue Research in Steel Structures, National Council of Structural Engineers Associations (NCSEA), 2009 http://www.structuremag.org/ article. aspx?articleID=850. Accessed 02/03/2012.

10. Pardoen, T., Scheyvaertsa, F., Simara, A., Tekoglu, C., and Onck P.R., Multiscale Modelling of Ductile Failure in Metallic Alloys. Comptes Rendus Physique, 11(3-4), April-May 2010, pp. 326-345

11. Besson, J., Steglich D., and Brocks W., Modelling of crack growth in round bars and plane strain specimens, International Journal of Solids and Structures, 38, 2001, pp. 8259-8284.

12. Scheider, I. and Brocks, W., Simulation of CupCone Fracture using the Cohesive Model, Engineering Fracture Mechanics, 70, 2003, pp. 1943-1961.

13. Anderson T.L., Fracture Mechanics Fundamentals and Applications, 2005, Third edition. CRC press, Taylor and Francis Group, ISBN 10:08493-1656-1. 
14. Xue, L., Damage Accumulation and Fracture Initiation in Uncracked Ductile Solids Subject to Triaxial Loading. International Journal of Solids and Structures, 44(16), 2007, pp. 51635181.

15. Kim, Y and Chao Y.J., Numerical Simulation of Cup-Cone Fracture in a Round Tensile Bar, Proceedings of PVP2008, 2008 ASME Pressure Vessel and Piping Division Conference, July 283, 2008, Chicago, Illinois, USA.

16. Panontin, T.L. and Sheppard, S.D., The Relationship between Constraint and Ductile Fracture Initiation as Defined by Micromechanical Analysis, Fracture Mechanics, 26, 1995, ASTM international, ISBN 0-8031-1996-8, pp. 54-85.

17. Tvergaard, V and Needleman A., Analysis of the Cup-Cone Fracture in a Round Tensile Bar, Acta Metallurgica, 32(1), 1984, pp. 157-169.

18. Adewole, K.K., Identification of Appropriate Micromechanical Fracture Model for Predicting
Fracture Performance of Steel Wires for Civil Engineering Applications. Global Journal of Researches in Engineering, Civil and Structural Engineering, 13(3), 2013, Version 1.0, pp. 24-34.

19. ASTM E8M, 2009, Standard Test Method for Tension Testing of Metallic Materials, American Society for Testing of Materials.

20. BS EN 10002-1:2001. Tensile Testing of Metallic Materials. Method of Test at Ambient Temperature, British Standards Institutes.

21. Celentano, D.J., and Chaboche, J., 2007. Experimental and Numerical Characterization of Damage Evolution in Steels. International Journal of Plasticity, 23, 2007, pp. 1739-1762.

22. Kut, S., The Application of the Formability Utilization Indicator for Finite Element Modelling the Ductile Fracture during the Material Blanking Process. Materials and Design, 31(7), August 2010, pp. 3244-3252. 